\title{
Role of vitamin Ain the healing process of alkali caused cornealinjury of adult male albino rat: Histological and immunohistochemical study
}

\author{
Original Soha Abd El Kawi Abdelwahab ${ }^{1}$, Entesar Ali Saber ${ }^{2}$, Ahmed Sayed ${ }^{1}$, and Nahla \\ Article \\ Mohammed Abd El-Hameed ${ }^{l}$
}

\author{
${ }^{1}$ Histology Department, Faculty of Medicine, Minia University, Minia, Egypt \\ ${ }^{2}$ Histology Department, Faculty of Medicine, Minia, Egypt, Delegated to Deraya University, \\ New Minia, Egypt.
}

\begin{abstract}
Background and Aim: Alkali burn of the cornea is considered as the most dangerous injury to the eye. It causes corneal infection, ulceration, perforation, neovascularization (NV) and opacification. Vitamin A is necessary for the normal growth and differentiation of epithelium; it is expected to promote the mechanical repair of corneal epithelial defects

The present study is planned to investigate the effect of vitamin A eyegel on wound healing of the corneal alkali burn in rats. Materials and Methods: A total of thirty male albino rats were used. Rats were divided randomly into four groups: Group I, the control group; included three rats, received distilled water. Each of group II, III, IV included 9 rats: their central corneas of the right eyes were injured by contacting them with filter paper saturated with $0.01 \mathrm{~m} \mathrm{NaOH}$ for 45 seconds. Group II, the non-treated group, injured and received distilled water. Group III, the antibiotic treated group, received antibiotic eye drops (lincomycin hydrochloride eye drops) 3 times per day for 3 days. Group IV, vitamin A treated group, received the same course of antibiotic and vitamin A eye gel (Hypotear gel $1000 \mathrm{IU} / \mathrm{g}$ ) three times per day. for 3 days. The eyeball was taken out, rapidly fixed and processed for light microscopic, immunohistochemical and morphometric studies. Specimens were taken after 24, 48 and $72 \mathrm{hr}$. post-injury for tissue preparation and study of structural changes and immuno-histochemical analysis using Ki67 (detection of cellular proliferation) and transforming growth factor - beta (TGF- $\beta$ ) which is one of the most critical growth factors in establishing the pathologic lesion after corneal alkali burn.

Results: Hematoxylin and eosin stained sections showed rapid healing of corneal ulcer in vitamin A treated group, with absence of neo-vasculariztion and inflammatory cellular infiltration. Immunohistochemical results showed that the use of vitamin A enhance cell proliferation (detected with Ki67) and decrease the expression of TGF- $\beta$ which is one of the most critical growth factors in establishing the pathological lesion after corneal alkali burn.

Conclusions: Vitamin A eye gel helped rapid healing of corneal alkali burn. This effect may be due to its anti-inflammatory effect and stimulation of cell proliferation.
\end{abstract}

Key Words: Alkali burn, cornea, vitamin A

Revised: 1 May 2017, Accepted: 3 May 2017

Corresponding Author: Soha Abdelkawi Abdelwahab, Tel.: 01113069333, E-mail: aspb2017@gmail.com

ISSN: 2536-9172, May 2017, Vol. 1, No. 1

\section{INTRODUCTION}

Corneal clarity and good visual quality are obtained through a highly ordered tissue architecture and lack of vascularization $^{[1]}$. Alkali injury of the cornea is one of the most dangerous injuries to the eye. Corneal alkali burns cause corneal infection, ulceration, perforation, neovascularization (NV) and opacification ${ }^{[2]}$. The cornea is a physiologically transparent tissue; the balance between angiogenic and antiangiogenic factors determines the regulation of corneal NV after a corneal alkali burn.

TGF- $\beta$ has the ability to induce the expressions of cytokines, such as matrix metalloproteinase 9
(MMP 9), vascular endothelial growth factor A (VEGF-A) and monocyte/ macrophage chemotactic protein-1, which are believed to be involved in matrix degradation, local neovascularization and inflammation, respectively. Transforming growth factor beta (TGF- $\beta$ ) also initiates conversion of keratocyte to myofibroblast after a corneal $\operatorname{burn}^{[3]}$.

Central corneal epithelium contains a rapidly proliferating basal cell layer, which helps maintain the thickness of the epithelium by replacing cells lost from the corneal surface, and terminally differentiated into suprabasal cell layers. Within the limbal region of the epithelium is a slow cycling stem cell population located in the basal 
cell layer. In the event of injury limbal epithelial stem cells (LESCs) can become highly proliferative ${ }^{[4]}$.

Vitamin A is necessary for the normal growth and differentiation of corneal epithelium. Vitamin A palmitate may promote the repair of mechanical corneal epithelial defects $^{[5]}$.

The present work was planned to study the role of vitamin A eye gel in the healing process of alki induced corneal injury and to shed a light on the possible mechanisms underlying this effect.

\section{MATERIALS AND METHODS}

\section{Animals}

This study was conducted in the Histology Department Faculty of Medicine Minia University, Minia, Egypt. The study was dealing with the corneal tissues of male albino rats. Thirty rats, specific pathogens free at the age of 68- weeks weighing 150-200 grams, were used. Animals were housed in clean plastic cages in an air conditioned room under a 12 hours light/ dark cycle.

All animals became acclimatized for at least 7 days before the outset of the study and were given food and water ad-libitum and were kept at constant humidity and temperature. The experiment was approved by the ethical committee for animal handling for research work in Minia University.

In vivo animal model of corneal epithelial wound healing.

Rats were deeply anesthetized by an intra-peritoneal (i. p.) injection of $50 \mathrm{mg} / \mathrm{kg}$ tiletamine plus zolazepam and $15 \mathrm{mg} / \mathrm{kg}$ xylazine hydrochloride. In each case, the central cornea of the right eye was injured by placing a tip of filter paper saturated with $0.01 \mathrm{~m} \mathrm{NaOH}$ (Sigma Aldrich Germany) on it for 45 seconds $^{[6]}$.

Group I: The normal cornea of rats were not injured but received only distilled water.

Group II: The central cornea of rats were injured and received only distilled water.

Group III: Injury to the central cornea was done in the same way as group I, followed by application of antibiotic (lincomycin hydrochloride eye drops (Boen pharm) eye drops ( 2 drops each time) 3 times per day for 3 days $^{[5]}$.

Group IV: Injury to the central cornea was done, followed by application of both antibiotic eye drops and vitamin A eye gel (hypotear eye gel retinol palmitat1000 $\mathrm{IU} / \mathrm{g}$ Alcon) 3 times per day for 3 days $^{[7]}$.
Three rats from each group were sacrificed after 1, 2, 3 days by decapitation under light halothane anesthesia. The specimens of the corneas were fixed in $10 \%$ formal saline for 48 hours and then specimens were processed to prepare paraffin sections for morphological studies.

\section{a) $H \& E$ staining:}

Specimens were taken from the eyeball and fixed in $10 \%$ formal saline for one or two days, followed by dehydration, then put in xylene, and embedded in paraffin.

Serial transverse sections of $56-\mu \mathrm{m}$ thick were cut by a rotatory microtome and mounted on coated glass slides ${ }^{[8]}$.

\section{b) Immunohistochemical studies:}

\section{1-Immunocytochemical staining was performed using:}

- Monoclonal mouse antibodies (ki67/MKI67 antibody) which were obtained from Sigma Aldrich (Germany).

- Polyclonal rabbit anti-Transforming Growth Factor $-\beta$ (TGF- $\beta$ ), obtained from Sigma Aldrich (Germany).

\section{Immunohistochemistry was performed on paraffin sections:}

Sections were de-paraffinized by heating overnight at $60^{\circ} \mathrm{C}$ and soaking in xylene, and were rehydrated in descending grades of ethanol. Antigen retrieval was performed with citrate buffer $(\mathrm{pH} \mathrm{6})$ at $97^{\circ} \mathrm{C}$ for 20 min. Endogenous peroxidase activity was blocked with hydrogen peroxide in methanol at room temperature for $30 \mathrm{~min}$. Non-specific antigens were blocked with incubation in $0.3 \%$ bovine serum albumin in Tris-buffered saline/Tween for $30 \mathrm{~min}$. Slides were then incubated with anti- Ki-67 mouse monoclonal antibody (1:100 dilution) for $1 \mathrm{~h}$ at room temperature and with anti-Transforming Growth Factor $\beta$ over night at $4^{\circ} \mathrm{C}$. Sections then were washed 3 times each for 5 minutes in buffer and incubated for further 30 minutes with biotinylated goat antirabbit secondary antibodies diluted 1:1000, followed by washing. Incubated for 30 minutes with Vectastain ABC kits (Avidin, Biotinylated horse radish peroxidase Complex) and washing for 10 minutes. The substrate, diaminobenzidine tetra hydrochloride (DAB) in distilled water was added for 510- min. The enzyme reaction was developed as described previously. The slides were lightly counterstained by Mayer's hematoxylin. +ve control for Ki67 was the tonsil and that for TGF $\beta$ was breast cancer, -ve control was performed by omitting the step of 1ry antibody application ${ }^{[9]}$.

\section{Photography}

Slides were photographed using Olympus digital camera connected to an Olympus light microscope (BX51). (Olympus Japan). 


\section{Morphometric and Statistical analysis:}

The procedures utilized a hardware consisting of a highresolution color digital camera mounted on an Olympus BX51 microscope and connected to a computer. Three sections were examined from each of all animal included in each group of the experiment.

The analysis has been performed on 10 different adjacent non overlapped fields for the same slide. Three different sections of the same animal were used. The number of examined animals was ten control rats and ten of each treatment. The number of Ki67 immuno-positive nuclei was counted and analyzed. Statistical analysis was done by SPSS version 19, windows 2008. The mean number (MN) and standard deviation (SD) were determined for parameter in each group. The significance of differences observed in these groups was pooled and assessed by parametric test (ANOVA) and Post hoc test ${ }^{[10]}$.

\section{RESULTS}

\section{Hematoxylin and eosin results:}

\section{Group I (Control)}

Sections showed stratified squamous non keratinized epithelium resting on basal lamina (Bowman's layer) that appeared as acellular layer. Stroma contains keratocytes within acidophilic parallel regular lamella of collagen. Endothelial cell nuclei are seen in a single layer beneath the Descemet's membrane (Fig. 1).

\section{Group II (Non-treated Alkali Injured Cornea)}

Sections after one day showed complete epithelial loss and flat basal cells. The anterior stroma showed cell infiltration. Disorganized separated collagen fibers and disorganized keratocytes were observed. Descemet's membrane appeared thickened (Fig. 2A).

After 2days multiple cells with flattened darkly stained nuclei (arrowhead) and vacuolated cells were found. Stroma showed increased separation and disruption of collagen fibers and disorganized keratocytes (Fig. 2B). After three days, the epithelium revealed superficial ghost nuclei, few basal vacuolated cells and other cells with darkly stained nuclei. Collagen separation and disorganized keratocytes were still observed (Fig. 2C).

\section{Group III (Antibiotic treated Cornea)}

After 1day sections showed irregular surface, some obviously vacuolated superficial epithelial cells and some obviously vacuolated basal cells. Stroma recruited homogenous collagen and some widely separated collagen fibers can be observed (Fig. 3A).

After 2days, some basal and suprabasal cells contained flat darkly stained nuclei. The basement membrane is not clear in certain areas. Homogenous collagen and less separation of collagen were observed (Fig. 3 B).

After 3days the epithelium revealed superficial ghost nuclei, few basal and supra-basal vacuolated cells. The stroma showed slightly separated, and more or less regularly arranged collagen bundles (Fig. 3 C).

\section{Group IV (Vit.A and Antibiotic treated Cornea)}

After one day minimal irregularity of the surface, few basal vacuolated cells and intact basal lamina. Separation of some collagen bundles and keratocytes were regularly arranged (Fig. 4 A).

After two days regular surface and few basal cells appeared vacuolated. Stroma showed slightly separation of collagen fibers (Fig. 4 B). After 3 days the corneal epithelium appeared more or less normal, with minimal separation of collagen fibers (Fig. 4 C).

\section{Immunohistochemical results for Ki67:}

\section{Group I}

The normal cornea of group I showed negative Ki67 immunoexpression (Fig. 5).

\section{Group II}

After one day Ki67 few positive nuclei were found in the basal epithelial layer of the central cornea and few positive nuclei at the periphery of the cornea (Figs. $6 \mathrm{~A}$ and $\mathrm{B}$ ).

After two days few positive nuclei were seen in the basal epithelium, while after 3 days more numerous positive Ki67 nuclei could be observed (Figs. $7 \mathrm{~A}$ and $\mathrm{B}$ ).

\section{Group III}

After one day some basal and supra-basal Ki67 positive nuclei were detected at the central cornea and few basal positive nuclei at the peripheral cornea (Figs. $8 \mathrm{~A}$ and $\mathrm{B}$ ).

After two days some basal positive nuclei were found at the central cornea and after three days fewer basal positive nuclei (arrow) were seen at the central cornea (Fig. 9 A and B).

\section{Group IV}

After one day few positive nuclei were seen in the basal epithelial layer of the central cornea and multiple positive nuclei at the periphery of the cornea (Figs. $10 \mathrm{~A}$ and B).

After two days some positive basal nuclei and after three days few positive nuclei were detected (Figs. 11A and B). 


\section{Immunohistochemical results for TFG- $\beta$ :}

\section{Group I}

Sections showed positive cytoplasmic expression for TGF- $\beta$ in keratocytes and some endothelial cells. Notice negative expression in the corneal epithelium (Fig. 12).

\section{Group II}

After one day positive cytoplasmic expression in epithelial cells and in the stromal cells. After two days less positive expression in the epithelium and stroma. After 3days negative expression in the epithelium, while cells in the stroma still show obvious expression (Figs. $13 \mathrm{~A}, \mathrm{~B}$ and $\mathrm{C}$ )

\section{Group III}

After one day obvious cytoplasmic expression in the epithelium and minimal expression in the stroma were seen. After two days minimal expression in the epithelium and stroma was detected. After 3days negative expression was noticed (Figs. 14 A, B \&C).

\section{Group IV}

After one day minimal positive cytoplasmic expression in the epithelium and stroma was evident. After 2 and 3days negative expression was found in the epithelium (Figs. 15 A and B).

Morphometric analysis of the number of Ki67 positive cells :

\section{1- At day 1 and day 2:}

- There was a significant decrease in the mean number of Ki67 positive nuclei in group II compared to groups III and IV $(P<0.05)$.

\section{2- At day 3:}

-There was a significant increase in the mean number of Ki67 positive cells in groups II and III compared to group IV $(P<0.05)$ (Table I).

Table 1: showing the mean number of Ki67 positive cells for all experimental groups

$\begin{array}{ccc}\text { GII(non } & \text { GIII (antibiotic } & \text { GIV (vit. A } \\ \text { treated }) \mathrm{N}=6 & \text { treated) } \mathrm{N}=6 & \text { treated) } \mathrm{N}=6\end{array}$

$0.03 *$

GII vs GIII

GIII vs GIV

GII vs GIV

$1^{\text {st }}$ day

$5.4 \pm 1.7$

$7.6 \pm 1.5$

$7.6 \pm 1$

$0.05^{*}$

0.9

$0.05^{*}$

$0.02 *$

GII vs GIII

GIII vs GIV

GII vs GIV

$2^{\text {nd }}$ day

$2.8 \pm 1.5$

$7 \pm 3.4$

$4.6 \pm 1.4$

$0.02 *$

0.2

$0.04 *$

\begin{tabular}{ccccc}
$6.8 \pm 1.5$ & $2 \pm 1.8$ & GII vs GIII & GIII vs GIV & GII vs GIV \\
& & 0.5 & $0.001 *$ & $0.001 *$ \\
\hline
\end{tabular}

*Significant difference between groups ( $p$ value $\leq 0.05$ ). 


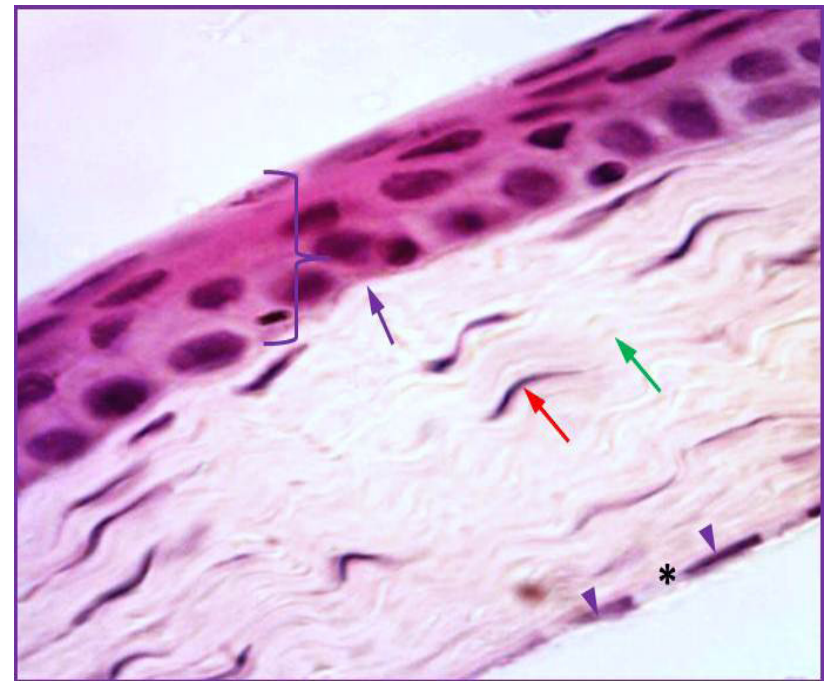

Fig. 1: Photomicrograph of a section in the cornea of group I showing; Stratified squamous non keratinized epithelium resting on basal lamina ( $\}$ ). Bowman's layer appears as acellular layer (blue arrow). Stroma contains keratocytes (red arrow) within acidophilic parallel regular lamella of collagen (green arrow). Endothelial cell nuclei are seen in a single layer (arrow head) beneath the Descemet's membrane $\left(^{*}\right)$.

(H \&E x400)

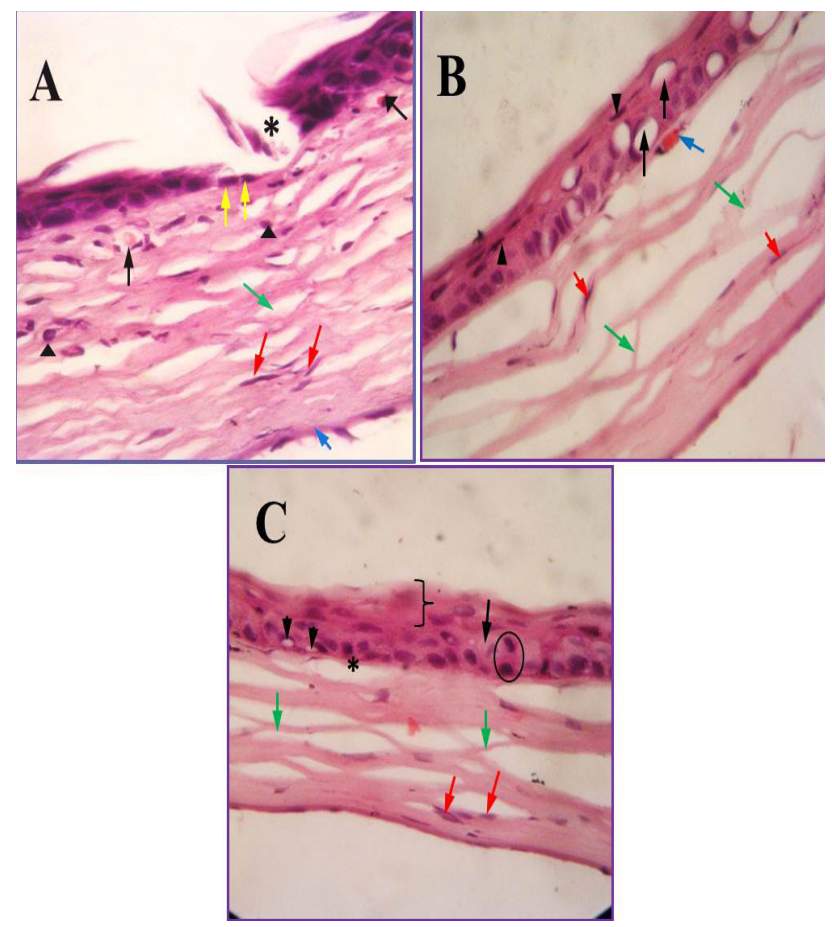

Fig. 2: Photomicrographs of group (II) showing:- (A) after one day complete epithelial loss $(*)$ and flat basal cells (yellow arrow). The anterior stroma shows cell infiltration (black arrow heads). Disorganized separated collagen fibers (green arrow) and disorganized keratocytes (red arrow). Descemet's membrane appears thickened (blue arrowhead) .(B) After 2days multiple cells with flattened dark nuclei (arrowhead) and vacuolated cells (arrow). Stroma shows increased separation and disruption of collagen fibers (green arrow) and disorganized keratocytes (red arrow). (C) the epithelium with superficial ghost nuclei ( $\}$ ). Few basal vacuolated cells (arrow heads), other cells have dark nuclei (circle). Collagen separation (green arrow) and disorganized keratocytes (red arrow) are still observed.

$(\mathrm{H} \& \mathrm{E} \times 400)$

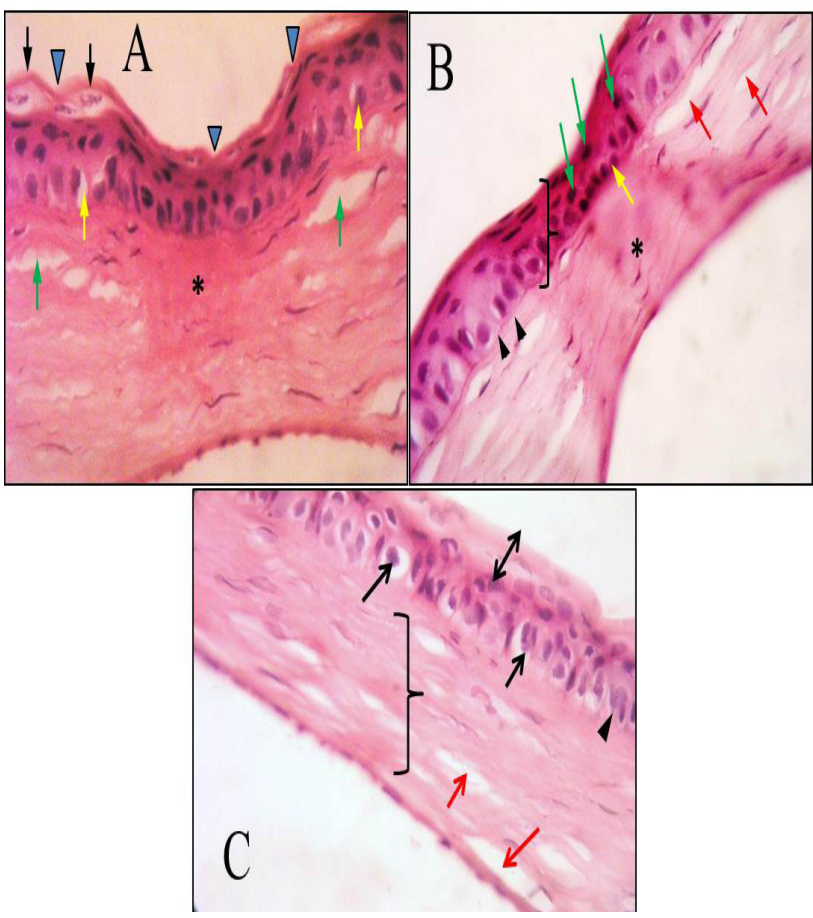

Fig. 3: Photomicrographs of group (III) showing:- (A) after 1day irregular surface (blue arrowheads), some obviously vacuolated superficial cells (black arrows) and some obviously vacuolated basal cells (yellow arrows). Stroma shows homogenous collagen $\left.{ }^{*}\right)$ and some widely separated collagen fibers can be observed (green arrows) (B) After 2days, basal cells (yellow arrow) and suprabasal cells (green arrow) with flat darkly stained nuclei. The basement membrane is not clear in certain areas (arrow heads). Homogenous collagen $\left(^{*}\right)$ and less separation of collagen (red arrow). (C) after 3days the epithelium reveals superficial ghost nuclei, few basal and supra-basal vacuolated cells (arrows).The stroma shows slightly separated (red arrow), and more or less regularly arranged collagen bundles.

$(\mathrm{H} \& \mathrm{E} \times 400)$

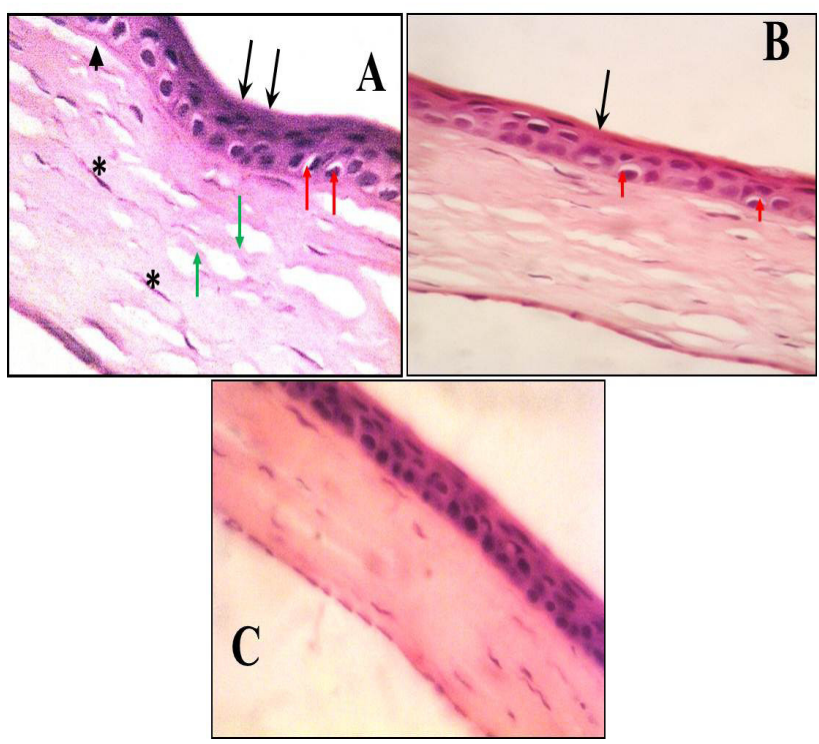

Fig. 4: Photomicrographs of group (VI) showing:- (A) After one day minimal irregularity of the surface (arrow), few basal cells appear vacuolated (red arrows), basal lamina is intact (arrow head) and separation of some collagen bundles (green arrow) Keratocytes are regularly arranged $(*)$. (B) after two days regular surface (arrow), few basal cells appear vacuolated (red arrows). Stroma show less separation of collagen fibers.(C) after 3 day the corneal epithelium appears more or less normal, with minimal separation of collagen fibers (arrow). (H\&E x400) 


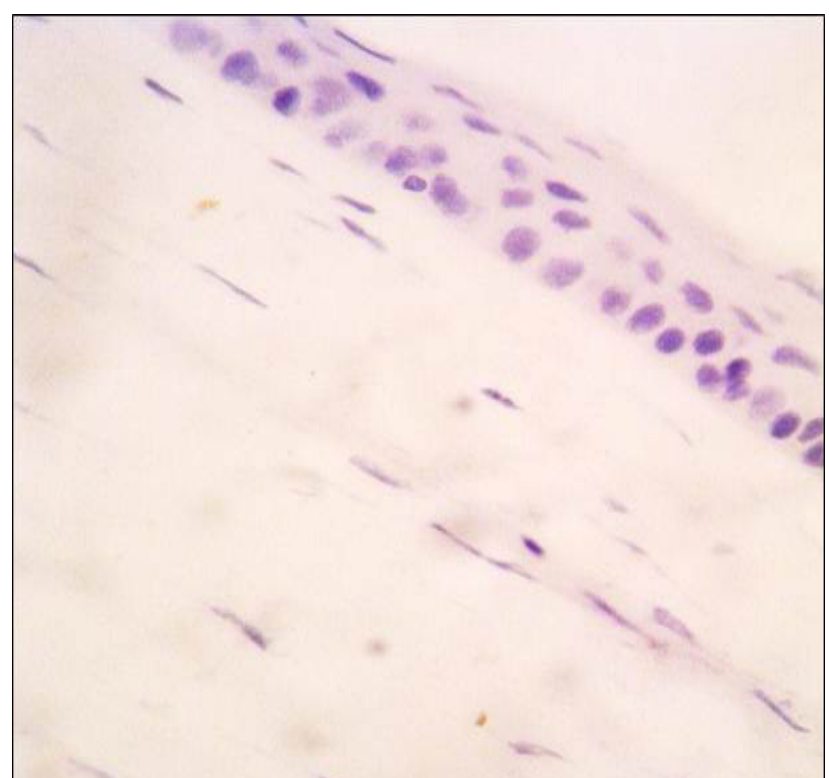

Fig5: A photomicrograph of a section in the cornea of group I showing: negative immunoexpression (Ki67 immunostaining $\mathrm{x} 1000)$

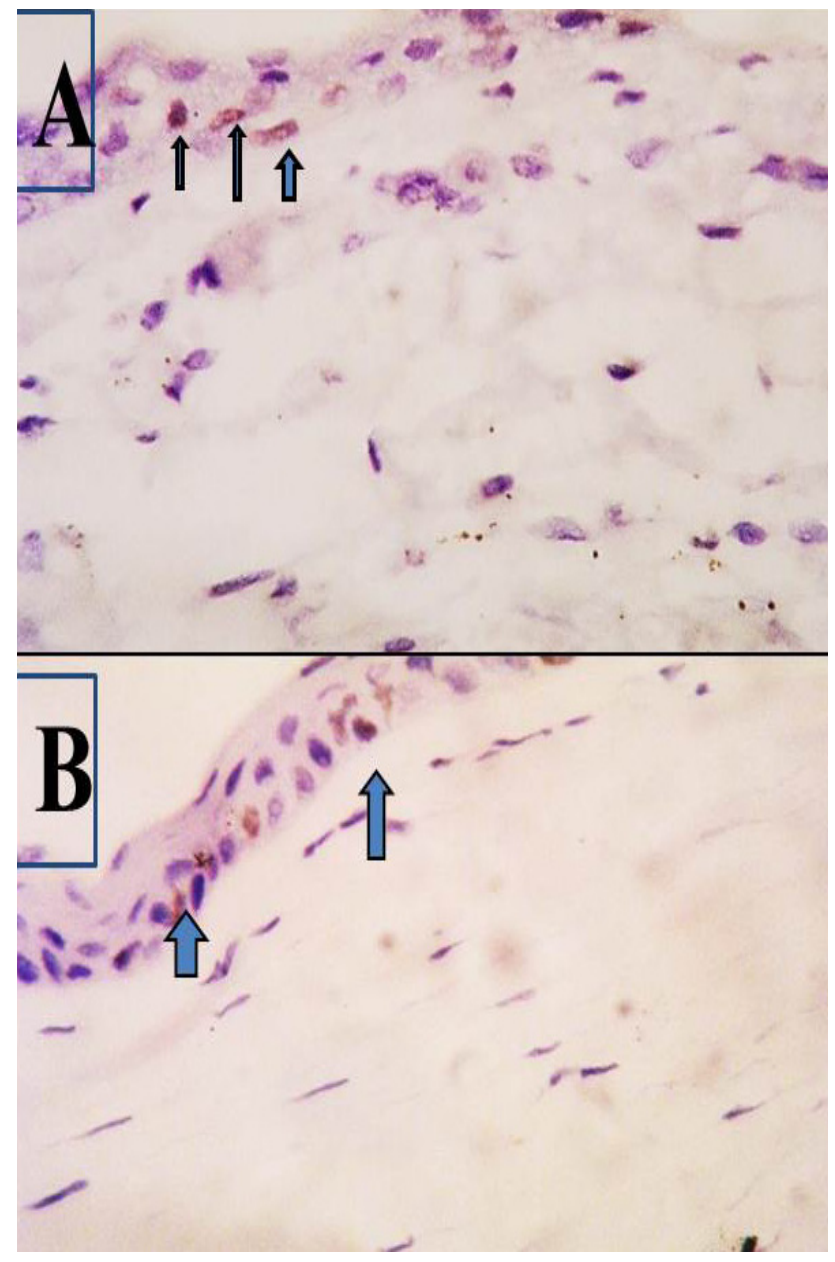

Fig. 6: Photomicrographs of sections in the cornea of group (II) after day1 showing:- (A) few positive nuclei in the basal epithelial layer (arrow) of the central cornea. (B). few positive nuclei at the periphery of the cornea.

(Ki67 immunostaining x1000)

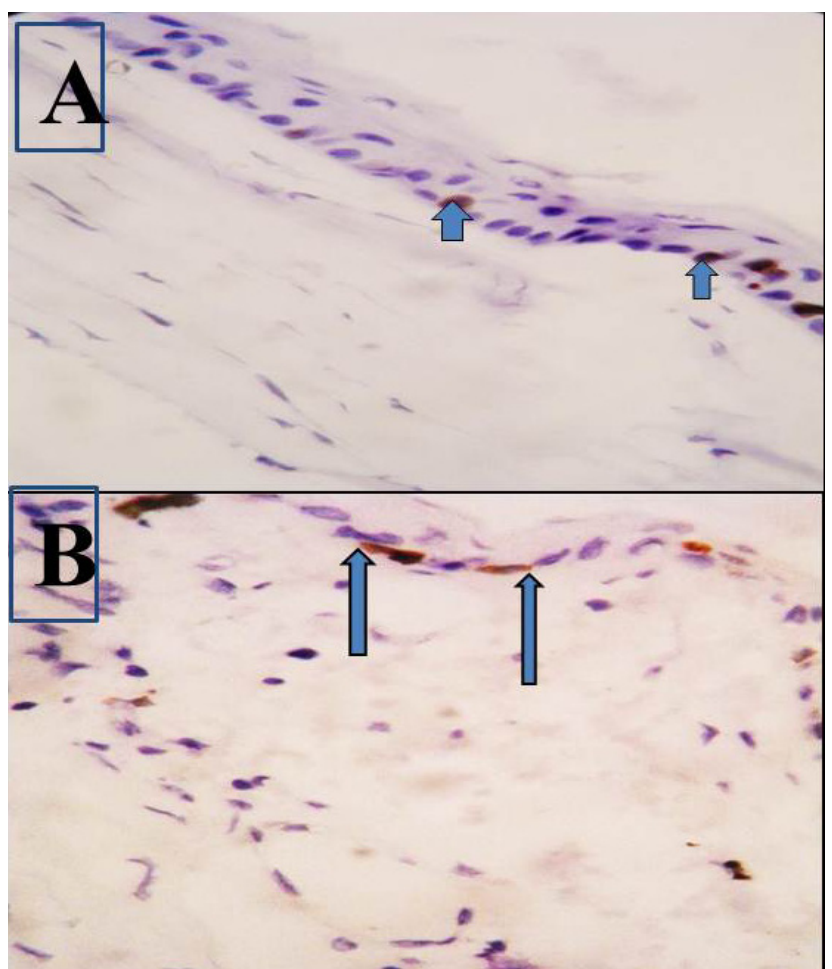

Fig. 7: Photomicrographs of sections in the cornea of group II showing (A) after two days, few positive nuclei (arrow) in the basal epithelium. (B) after 3 days showing more numerous positive nuclei (arrow) for Ki67.

(Ki 67 immunostaining x1000)

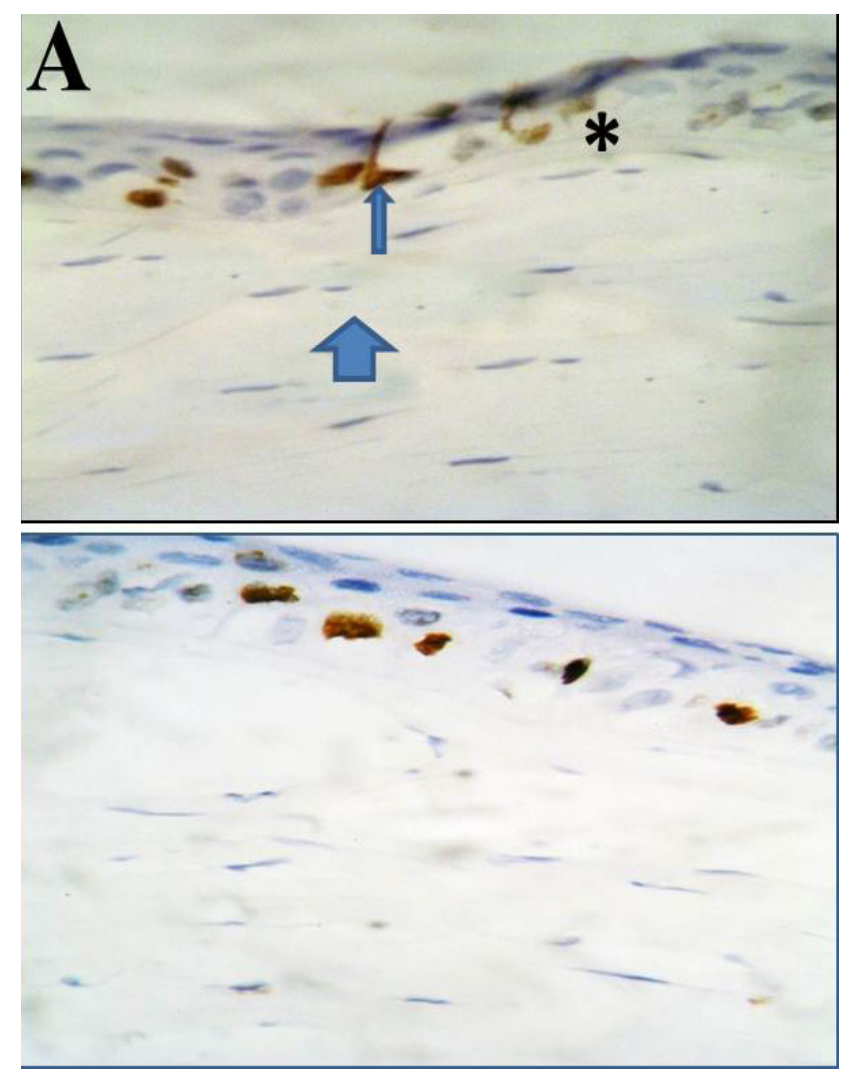

Fig. 8: Photomicrographs of sections in the cornea of group III showing: (A) After one day some basal (arrow) and supra-basal $\left(^{*}\right)$ positive nuclei at the central cornea. (B) After one day few basal (arrow) positive nuclei at the peripheral cornea. 


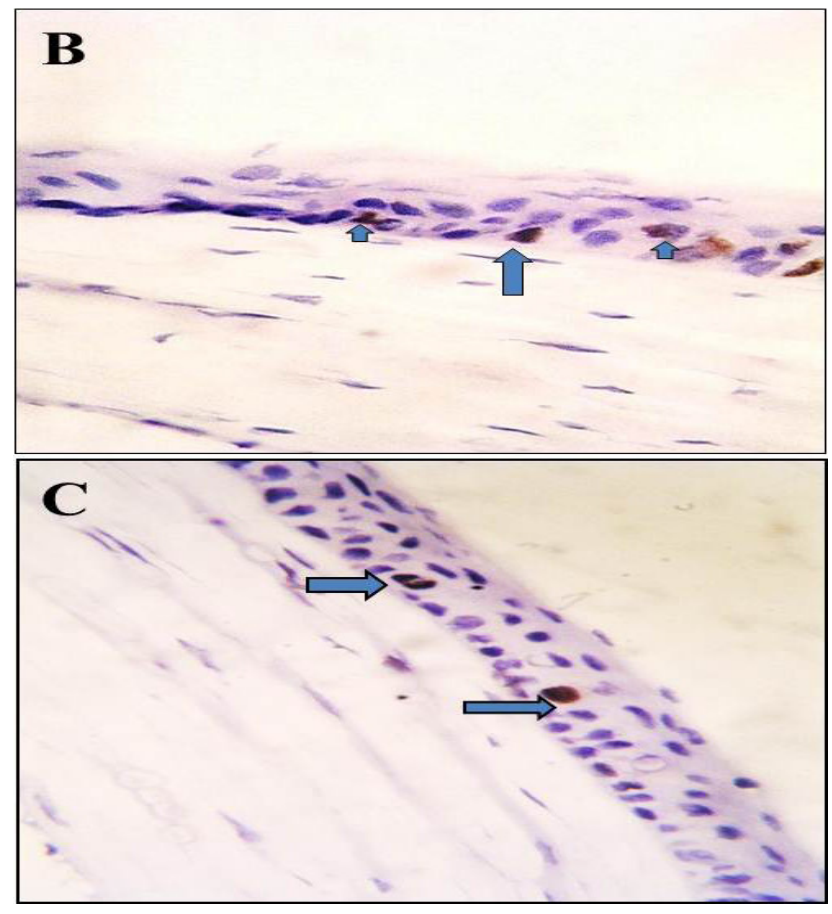

Fig. 9: Photomicrographs of sections in the cornea of group III showing: (A) After two days some basal positive nuclei (arrow) at the central cornea. (B) After three days fewer basal positive nuclei (arrow) at the central cornea.

(Ki67 immunostaining x1000)
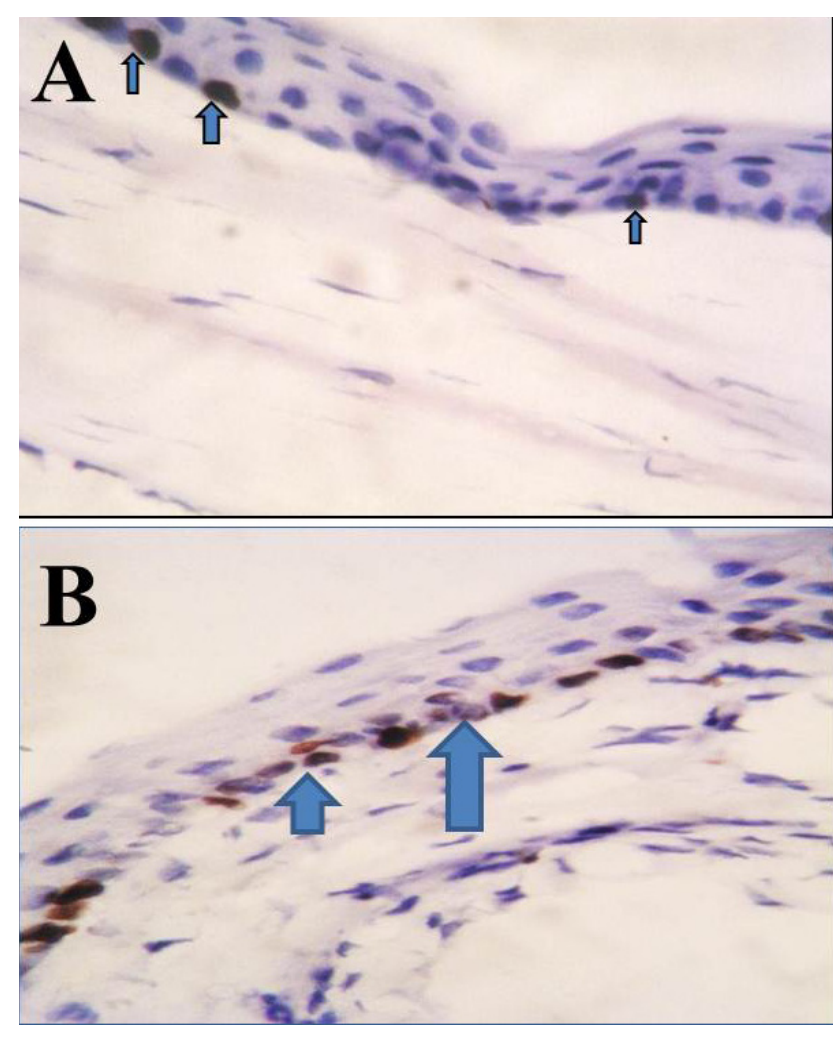

Fig. 10: Photomicrographs of sections in the cornea of group (IV) showing: (A) after day few positive nuclei in the basal epithelial layer (arrow) of the central cornea. (B). Multiple positive nuclei (arrow) at the periphery of the cornea.

(Ki67 immnuostaining x1000)

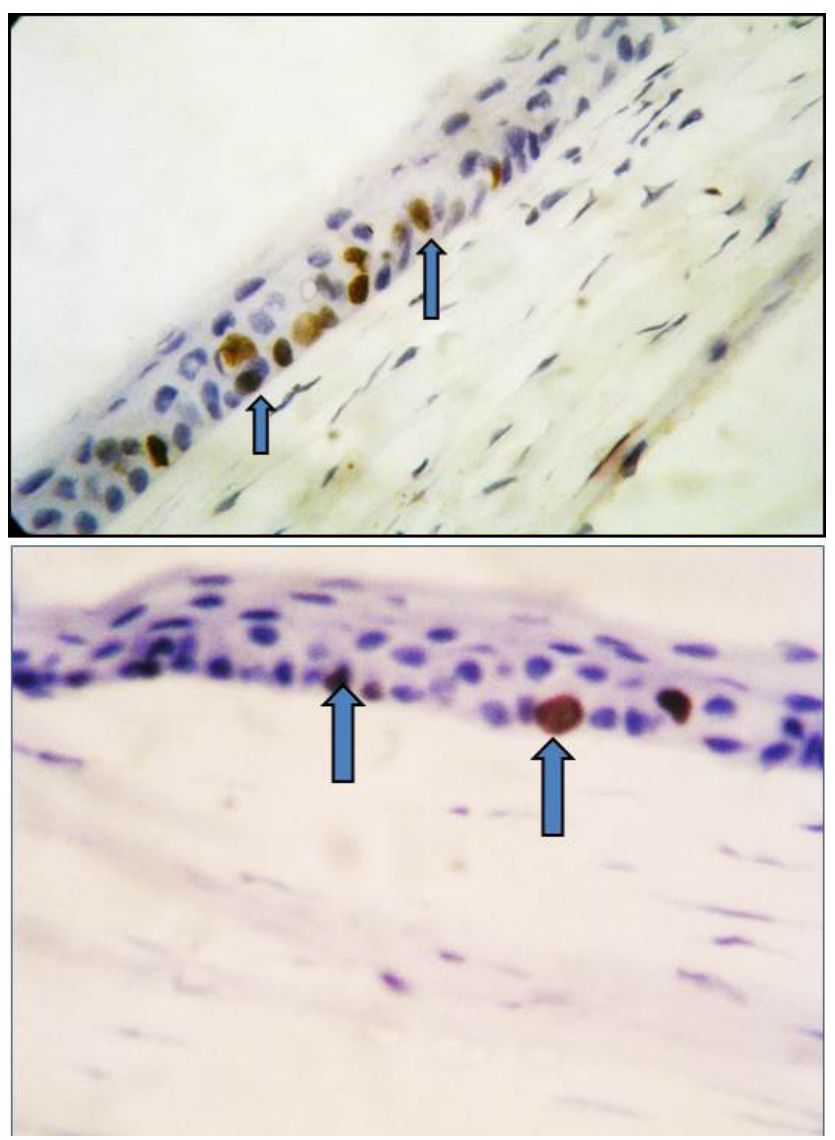

Fig. 11: Photomicrographs of the cornea of group (IV) showing: (A) after two days some positive basal nuclei (arrow). (B) after three days few positive nuclei (arrow).

(Ki67 immnuostaining x1000)

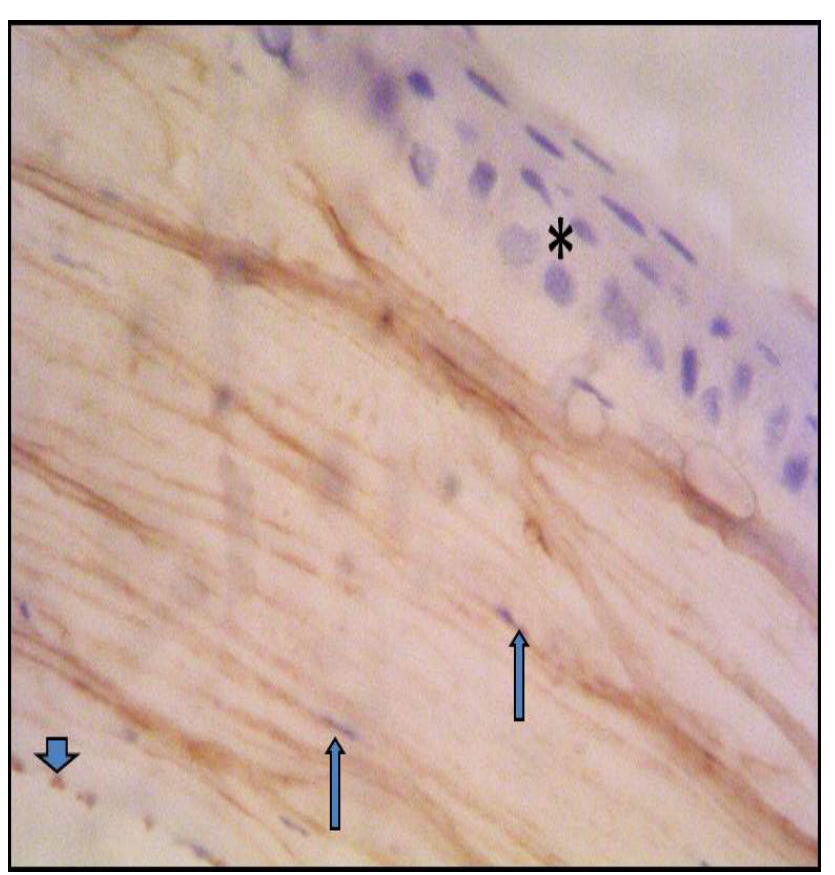

Fig. 12: A photomicrograph of a section in the cornea of group I showing; positive cytoplasmic expression in keratocytes (arrow) and some endothelial cells (arrowhead). Notice negative expression in the corneal epithelium $(*)$.

(TGF- $\beta$ immunostaining x 1000) 


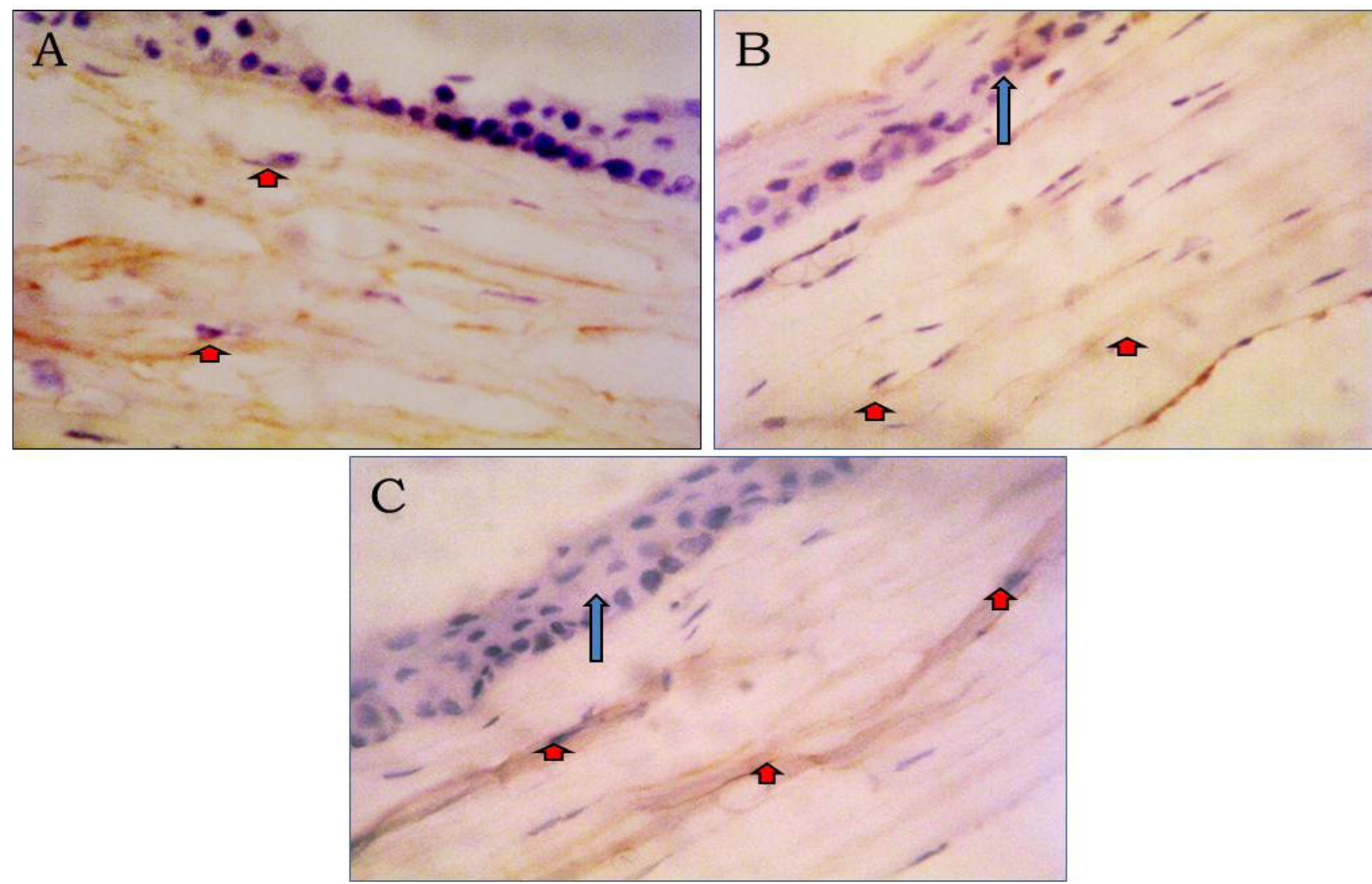

Fig. 13: Photomicrographs of sections of the cornea of group II showing : (A) after one day positive cytoplasmic expression in epithelial cells (blue arrow) and in the stromal cells (arrowhead). (B) after two days less positive expression in the epithelium and stroma. (C) after 3days negative expression in the epithelium, while cells in the stroma still show obvious expression.

(TGF- $\beta$ immunostaining x 1000)

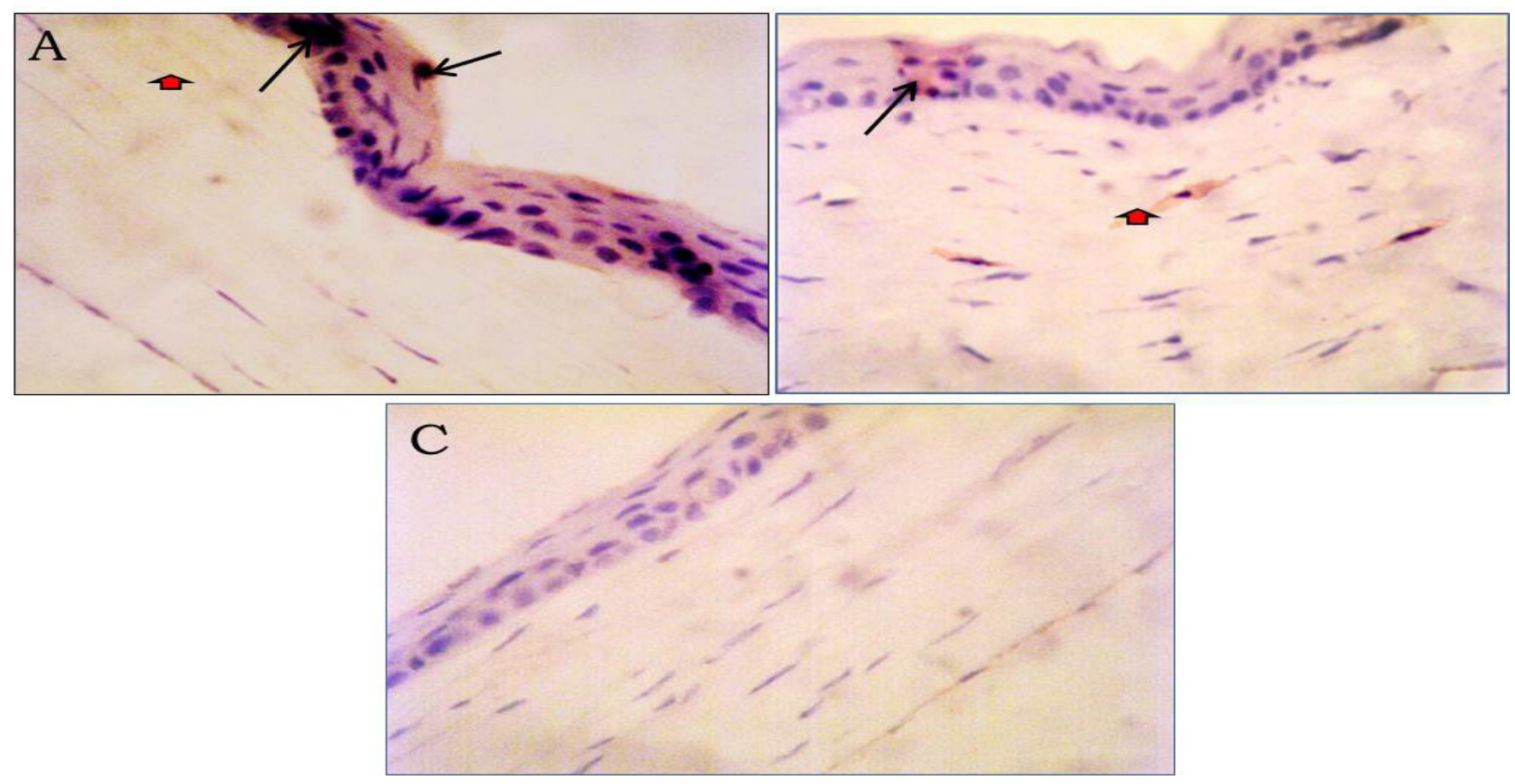

Fig. 14: Photomicrographs of sections in the cornea of group (III) showing (A) after one day obvious cytoplasmic expression in the epithelium (arrow) and minimal expression in the stroma (arrowhead) (B) after two days showing minimal expression in the epithelium (arrow) and stroma (arrow head). (C) after 3days showing negative expression.

(TGF- $\beta$ immunostaining x1000) 

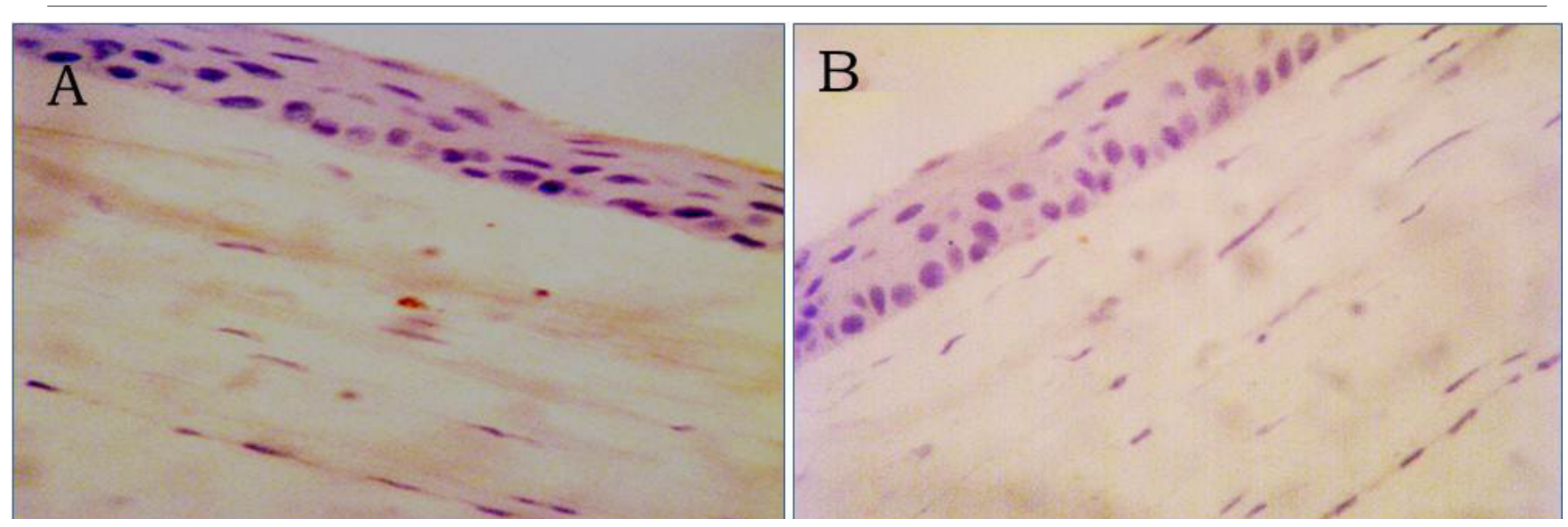

Fig. 15: Photomicrographs of sections in the cornea of group IV showing : (A) after one day showing minimal positive cytoplasmic expression in the epithelium (arrow) and stroma (arrowhead) (B) after 2 days negative expression in the epithelium.

(TGF- $\beta$ immunostaining $\times 1000)$

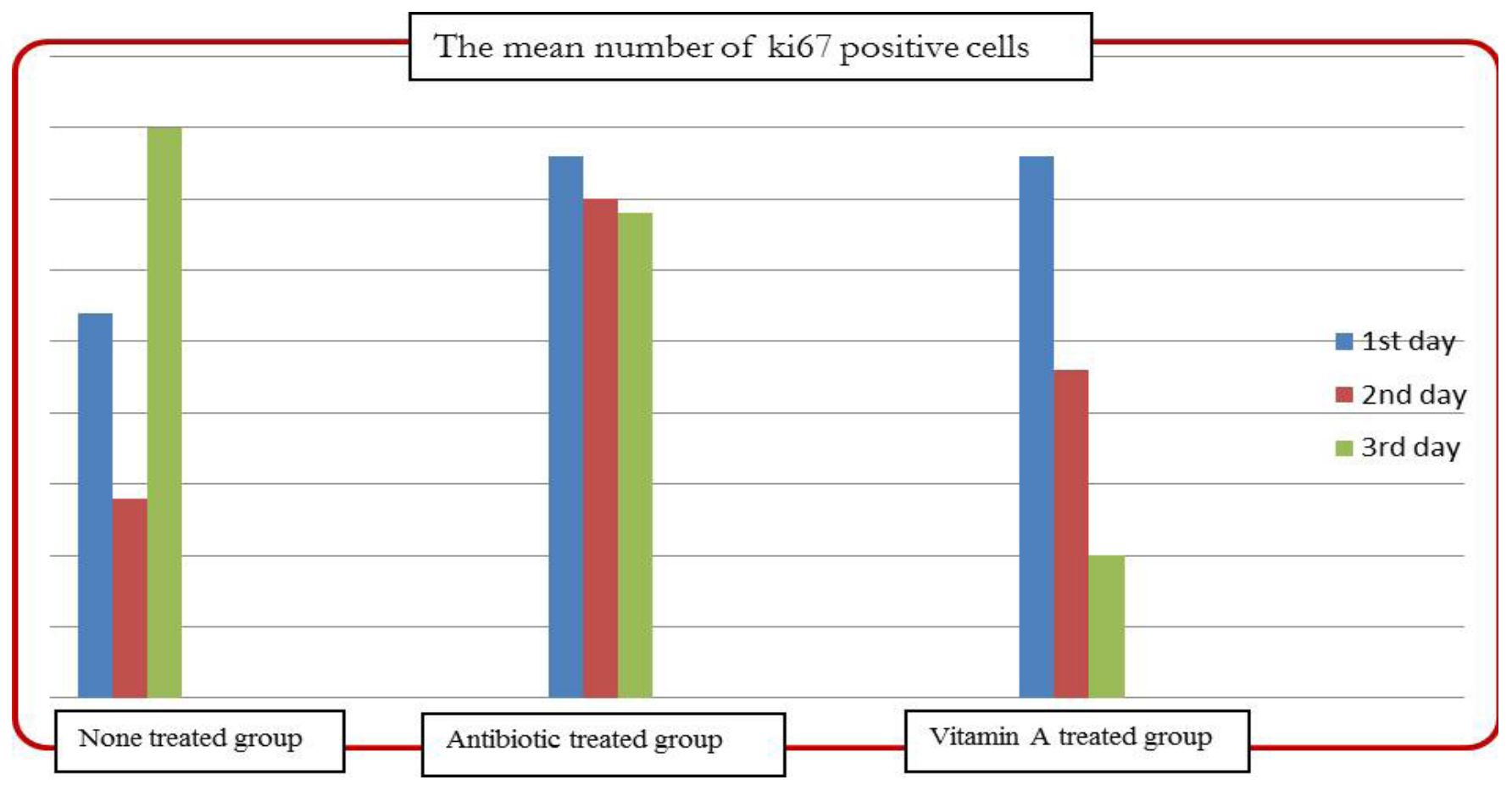

Fig. 16: Chart showing the mean number of Ki67 positive cells for all groups.

\section{DISCUSSION}

Corneal clarity and good visual quality are obtained through a highly ordered tissue architecture and lack of vascularization $^{[11]}$. Alkali injury of the cornea is one of the most dangerous injuries to the eye $\mathrm{e}^{[12]}$. The cornea has a real requirement for vitamin A (retinol) .Vitamin $\mathrm{A}$ is necessary for the normal growth and differentiation of epithelium, and its deficiency leads to increased epidermal keratinization and squamous metaplasia ${ }^{[13]}$.

In the present study, group II (non-treated group) after one day of $\mathrm{NaOH}$ corneal injury showed complete loss of the epithelium at the site of injury. The basal cells showed loss of its columnar appearance. It can be commented that there may be structural changes affecting the basement membrane on which these cells rest that lead to loss of its normal configuration.

Suzuki et al. ${ }^{[14]}$ explained that within 2 hours of the corneal wound, hemidesmosomal attachments between basal cells and the basement membrane disappear over an area extending 5070- $\mu \mathrm{m}$ from the wound edge. In support, Ashby et al. ${ }^{[15]}$ reported that corneal epithelial wound healing first phase is the latent phase as there is no change in number of cells.

The same group revealed attenuated basement membrane. It can be suggested that the damage affecting the basement membrane or the Bowman's 
layer on which epithelial cells are assembled to fill the defect, may initiate all the abnormal changes that occurred in the corneal tissue at the site of injury and may be the cause of the delay in the healing process of epithelial defect. This suggestion is in agreement with Torricelli et al. ${ }^{[16]}$ who reported that Bowman's membrane is critical in homeostasis and corneal wound healing. It acts as a barrier to penetration of inflammatory cytokines from the epithelium to stroma (such as TGF- $\beta 1$ ), and possibly from stroma to epithelium (such as keratinocyte growth factor).

In addition to the previous findings, inflammatory cellular infiltration and disorganized widely separated collagen fibers, indicating edema were observed. In accordance, Okada et al. ${ }^{[17]}$ added that the involvement of inflammatory cells and disorganization of collagen fibers in the wound healing process of an alkali-burned cornea leads to further release of fibrogenic cytokines that augment the tissue inflammation and subsequent corneal scarring. Also this was in agreement with Torricelli et al. ${ }^{[16]}$ who stated that highly disorganized extracellular matrix was observed in corneas with haze. In group II disorganized keratocytes were noticed. Going with, Wilson et al. ${ }^{[18]}$ considered keratocyte morphological changes as the earliest stromal event noted following epithelial injury and still a target for modulation of the wound healing response. These findings supported by Thaer et al. ${ }^{[19]}$ who stated that morphological changes of keratocytes were seen in all cases of corneal edema in corneal injuries (physical, chemical, or infectious) ${ }^{[20]}$ mentioned that the corneal opacity develops as a result of diminished transparency of the keratocytes themselves and the production of disordered extracellular matrix components by stromal cells.

In group II at day two after the corneal injury, there was vacuolation that may indicate hydropic degeneration of some epithelial cells, basal and supra-basal. It can be suggested that this was a compensatory mechanism through which the epithelial cells surrounding the sloughed area increased their volume as a trial to occupy a wider surface area to close the defect. This was in agreement with Jialin et al. ${ }^{[21]}$ who reported that in wound healing of the corneal tissue in mice, there was a dramatic rise in cell water content which increased the cell volume allowing it to cover a large area. They added that both basal and supra-basal cells participate in the migration process.

Other cells of group II showed apoptosis. This was supported by Estil et al. ${ }^{[22]}$ who considered that damaged cells undergo apoptosis and are soon shed into the tear film. While on day three, it showed epithelium which completely filled the gap, but revealed superficial keratinization, seen as lost or ghost nuclei. Few basal vacuolated cells, other cells had apoptotic nuclei. Some cells with ghost nuclei (chromatin lysis) were observed. Stromal edema reduced and disorganized keratocytes were found. All these morphological manifestations indicated incomplete regeneration process. This was supported by Wilson et al. ${ }^{[18]}$ considered that epithelial mitosis and migration, stromal cell disorganization, myofibroblast generation and inflammatory cell infiltration contribute to the wound healing cascade which is modulated by cytokines derived from corneal cells, the lacrimal gland and possibly immune cells.

Regarding immune-histochemical results of this study ki67 antibodies were used for detection of the proliferating cells as reported by Bruno and Darzynkiewicz ${ }^{[23]}$.

In group II, using ki67 antibodies showed a significant decrease in the mean number of positive nuclei at one and two days post-injury if compared with the corresponding days of groups III (antibiotic treated) and IV (vitamin A and antibiotic treated), indicating low proliferative capacity. While at the third day positive nuclei started to increase. Basal and supra-basal corneal epithelial cells have the ability to proliferate and replace the defect. That was supported by Joyce et al. ${ }^{[24]}$ who reported that corneal epithelium contains a rapidly proliferating basal cell layer, which helps to maintain the thickness of the epithelium by replacing cells lost from the corneal surface.

Considering transformin $0.5 \mathrm{~g}$ growth factor-beta (TGF- $\beta$ ) as one of the most critical growth factors in establishing the pathologic lesion after corneal alkali burn including the formation of corneal haze as reported by Ebihara et al. ${ }^{[25]}$. Myrna et al. ${ }^{[26]}$ stated that after corneal alkali injury, the corneal epithelium secretes growth factors and cytokines, including TFG- $\beta$.

In group II, there was obvious IE at day one which became less obvious later on. This may explain that the inflammatory reaction subsided gradually. These results were supported also by Kout et al. ${ }^{[27]}$ who mentioned that TFG- $\beta$ protein was secreted by both stressed epithelial cells and keratocytes. Wilson ${ }^{[20]}$ mentioned that transformation of keratocytes into myofibroblast is induced by TGF- $\beta$. Myofibroblasts establish an interconnected meshwork of cells and extracellular matrix that deposits new matrix and contracts corneal wounds.

\section{CONCLUSION}

Vitamin A dampens the damage resulting from injury of the corneal tissue through decreasing the level of TGF- $\beta$ and stimulating proliferation and differentiation of epithelial stem cells that are considered the main source of new cell formation. 


\section{RECOMMENDATION}

While handling any dangerous substance we must pay attention to avoid exposing the eye to their hazardous effects. If this cannot be avoided and the eye is injured adding of vitamin A to the treatment regimen is of great help to enhance the healing process. .

\section{CONFLICT OF INTEREST}

There are no conflicts of interest

\section{REFERENCES}

1. Hassell, J R, Birk, D E. The molecular basis of corneal transparency. Exp Eye Res (2010); 91: $326-335$.

2. Salman, IA, Gundogdu, C. Epithelial healing in experimental corneal alkali wounds with non diluted autologous serum eye drops. Cutan Ocul Toxicol (2011) ; 29: 116- 121.

3. Saika $\mathrm{S}$, Ikeda $\mathrm{K}$, Yamanaka $\mathrm{O}$, Miyamoto $\mathrm{T}$, Ohnishi Y, Sato M, Muragaki Y, Ooshima A, Nakajima Y, Kao WW, Flanders KC, Roberts AB. Expression of Smad7 in mouse eyes accelerates healing of corneal tissue after exposure to alkali. Am J Pathol (2005); 166:1405-1418.

4. Lavker RM, Sun TT. Epithelial stem cells: the eye provides a vision. Eye (2003); 17: 937-942.

5. Qiu, XD., Gong, L. and Chen, MJ. Research on effects of vitamin A palmitate on repair of mechanical corneal epithelial defects and conjunctival goblet cells in rabbits. Zhonghua Yan Ke Za Zhi (2010); 46: 151-160.

6. Anderson C, Zhou Q, Wang S. An Alkali-burn Injury Model of Corneal Neovascularization in the Mouse Vis. Exp. (2014); 86: 151- 159.

7. Samarawickrama C, Chew S, Watson S. Retinoic acid and the ocular surface. Survey of Ophthalmology (2015); 60: 183- 195

8. Bancroft J, Gamble M. Theory and practice of histological techniques. 6th ed. Harcourt: Churchill Livingstone (2008); 126:127, 417, 422 and 425 .

9. El-Domyati $\mathrm{M}$, Wael $\mathrm{H}$, Noha M, Hamza A, Selwet M. Hair follicle changes following intense pulsed light axillary hair reduction: histometrical, histological and immunohistochemical evaluation. Archives of Dermatological Research (2017); 309(3):191- 200
10. Gouveia, R M, Connon C J. The Effects of Retinoic Acid on Human Corneal Stromal Keratocytes Cultured In vitro under serum-free conditions. invest ophthalmol vis Sci (2013); 54:7483-7491.

11. Chan M F, Li J, Bertrand A, Casbon A, Lin J, Maltseva I, Werb Z. protective effects of matrix metalloproteinase-12 following corneal injury. Journal of Cell Science (2013); 126: 3948-3960.

12. Bashkaran K, Zunaina E, Bakiah S, Sulaiman S, Sirajudeen K, Naik V. Anti-inflammatory and antioxidant effects of Tualang honey in alkali injury on the eyes of rabbits: Experimental animal study. BMC Complementary and Alternative Medicine (2011); 11:90- 97

13. Kim EC, Tai K K, Sang HP, Man S K. The wound healing effects of vitamin A eye drops after a corneal alkali burn in rats. Acta Ophthalmol (2012); 90: e540-e546.

14. Suzuki K, Saito J, Yanai R, Yamada N, Seki CT, $\mathrm{K}$, Nishida T. Cell-matrix and cell-cell interactions during corneal epithelial wound healing. Prog Retin Eye Res (2003):; 22(2):113- 133.

15. Ashby BD, Garrett Q, Willcox MDP.: Corneal injuries and wound healing- review of processes and therapies. Austin J Ophthalmol, (2014); 1(4): 1017

16. Torricelli A M, Vivek S, Santhiago RM, Wilson ES. The Corneal Epithelial Basement Membrane: Structure, Function, and Disease, Invest Ophthalmol Vis Sci. 2013; 54:6390-6400.

17. Okada Y, Reinach P S, Shira K, Kitano A, Winston W Y K, Flanders KC, Miyajima M, Hongshan L, Zhang J, Saika S. TRPV1 Involvement in Inflammatory Tissue Fibrosis in Mice The American Journal of Pathology, (2011); 178, (6): 2661-2663.

18. Wilson SE, Mohan RR, Ambrosio JR, Hong JW, Lee JS. The corneal wound healing response: cytokine-mediated interaction of the epithelium, stroma and inflammatory cells. (2001); 205: $625-637$.

19. Thaer SA, Mouhame A, Trevor G, James L, Dua H. Histological and confocal microscopy changes in chronic corneal edema: Implications for endothelial transplantation. Investigative Ophthalmology and Visual Science (2011); 52: $8206-8206$. 
20. Wilson SE. Corneal myofibroblast biology and pathobiology: generation, persistence, and transparency Exp Eye Res. 2012; 99:78- 88.

21. Jialin C, Jie L, Dongle L, ludvig J, Wei Z, Qingjun $Z$, Patrik D. Ascorbic acid promotes the stemness of control epithelial /progenitor cells and accelerates epithelial wound healing in the cornea. Stem Cell Transplantation Medicine (2017); 6:1356- 1365.

22. Estil S, Kravik K, Haaskjold E, Refsum SB, Bjerknes R, Wilson G. Pilot study on the time course of apoptosis in the regenerating corneal epithelium. Acta Ophthalmol Scand (2002); 80: $517-523$

23. Bruno S, Darzynkiewicz Z. Cell cycle dependent expression and stability of the nuclear protein detected by ki67 antibody in HL-60 cells. Cell prolif (1992); 25: 31- 40 .

24. Joyce NC, Meklir B, Joyce SJ, Zieske JD. Cell Cycle protein expression and proliferative status in human corneal cells investigative ophthalmology and visual Science, (1996); 37 (4), :646--654.

25. Ebihara N, Yamagami S, Chen L, Tokura $\mathrm{T}$, Iwatsu M, Ushio H, Murakami A. Expression and function of toll-like receptor 3 and 9 in human corneal myofibroblasts. Invest ophthalmol Vis Sci (2007); 48: 402- 411 .

26. Myrna KE, Pot SA, Murphy CJ. Meet the corneal myofibroblast: the role of myofibroblast transformation in corneal wound healing and pathology. Vet Ophthalmol (2009); 12: 25-27.

27. Kout A, Hewitt WA, Kim G, Sonja K, Richard M, Vishal J, Craig EJ, Shiwani S, Burdon PK. Association of TCF4 and CLU polymorphisms with Fuchs' endothelial dystrophy and implication of CLU and TGFBI proteins in the disease process European Journal of Human Genetics (2012); 20: 632-638.

28. Soliman ME, Mahmoud BL, Kafafy MA, El Haroun HM, Mohamed DM. Histological Changes in Cornea Following Repeated Exposure to Benzalkonium Chloride and the Possible Protective Effect of Topically Applied Sodium Hyaluronate. Nat Sci (2015); 13:64 -76.

29. Fasce F, Spinelli A, Bolognesi G, Rossi M, Gemma M. Comparison of BD Multivisc with the soft shell technique in cases with hard lens nucleus and Fuchs endothelial dystrophy. Eur J Ophthalmol (2007); 17:709- 713 .
30. Barboza MC, Barboza GC, Sergio F, Paulo EC, Sato EH. Induction of corneal collagen crosslinking in experimental corneal alkali burns in rabbits, Arq Bras Oftalmol (2014); 77: 310- 314.

31. Zamani M, Bazaz M, Assadi M. Corneal collagen crosslinking foe treatment of nonhealing corneal ulcers. J. Ophthalmic. Res (2015); $10: 16-20$.

32. Tabibian D, Mazzotta C, Hafez F. Corneal crosslinking in infectious keratitis. Eye and Vision (2016); 3:11

33. Yellore VS, Rayner SA, Aldave AJ. TGFB1induced extracellular expression of TGFBI and inhibition of TGFBI expression by RNA interference in a human corneal epithelial cell line. Invest Ophthalmol Vis Sci (2011); 2011; 52: 757-763.

34. Bantseev V, McCanna DJ, Driot JY, Sivak JG. The effects of toxicological agents on the optics and mitochondria of the lens and the mitochondria of the corneal epithelium. Cell Dev Biol (2008); 19:150- 159

35. Schrader S, Mircheff AK, Geerling G. Animal models of dry eye. Dev Ophthalmol (2008); 41: $298-312$.

36. Li Z, Choi W, Oh HJ, Yoon KC. Effectiveness of topical infliximab in a mouse model of experimental dry eye. Cornea (2012); 31: $525-531$.

37. Yazdanpanah G, Jabbehdari S, Djalilian AR Limbal and corneal epithelial homeostasis. Curr Opin Ophthalmol. (2017); 28: 000- 000

38. Martin LF, Rocha EM, Garcia SB, Paula JS. Topical Brazilian propolis improves corneal wound healing and inflammation in rats following corneal alkali burns. BMC Complementary and Alternative Medicine (2013); 13: 337.

39. Gallego MP, Ibares FL, Valsero MC, Cantalapiedra RR, Merayo LJ, Martinez MC. Effects of TGF $\beta 1$, PDGF-BB, and bFGF, on human corneal fibroblasts proliferation and differentiation during stromal repair. Cytokine (2017); 5: 94- 101

40. Kumar S, Duester G. Retinoic acid signaling in perioptic mesenchyme represses Wnt signaling via induction of Pitx2 and Dkk2. Dev Biol (2010); 340: $67-74$ 